\title{
Synthesis and Characterization of Ag Nanoparticles Addition on BPSCCO Superconducting Thin Films
}

\author{
Saad F. Oboudi, Mustafa Q. Mustafa \\ Department of Physics, College of Science, University of Baghdad, Baghdad, Iraq \\ Email: saadoboudi@gmail.com
}

Received 10 January 2016; accepted 13 February 2016; published 16 February 2016

Copyright (C) 2016 by authors and Scientific Research Publishing Inc.

This work is licensed under the Creative Commons Attribution International License (CC BY). http://creativecommons.org/licenses/by/4.0/

c) (7) Open Access

\begin{abstract}
The growth of epitaxial Ag nanoparticles doped (Bi, Pb)-2223 thin films on Si (111) substrates by pulsed laser deposition (PLD) and post-deposition oxygen annealing have been achieved. The phase identification and gross structural characteristics of synthesized films explored through $\mathrm{X}$-ray diffractometer reveal that all the samples crystallize in orthorhombic structure. DC electrical resistivity measurements were done by the standard four-probe method and the results showed improvement in $T_{c}$ by increasing Ag nanoparticles to $1.0 \mathrm{wt} \%$ which had a maximum enhancement in $T_{c}$ for all investigated films. The surface morphology investigated through scanning electron microscope (SEM) and atomic force microscopy (AFM) results showed that an increase in $T_{c}$ with the appropriate Ag nanoparticles addition in the samples is associated with the enhancement of Bi (Pb)-2223 phase formation.
\end{abstract}

\section{Keywords}

PLD, Thin Films Superconductors, Bi (Pb)-2223, Ag Nanoparticle

\section{Introduction}

Since the discovery of Bi-based superconducting systems, a tremendous amount of work concerning preparation, superconducting properties, and the structure of these compounds has been carried out [1] [2]; a variety of potential applications of bulk materials as well as thin films in a number of cryoelectronic devices [3]-[5] have been reported. The BSCCO system mainly contains three phases in the general formula $\mathrm{Bi}_{2} \mathrm{Sr}_{2} \mathrm{Ca}_{n} \mathrm{Cu}_{n+1} \mathrm{O}_{\mathrm{y}}$ (where $\mathrm{n}=0,1$ and 2 refers to the number of $\mathrm{CuO}_{2}$ layers which yields $10,85,110 \mathrm{~K}$ transition temperatures, respectively) which commonly have a multiphase structure. Although it is difficult to obtain pure high $T c$ phase 
$\mathrm{Bi}-2223$, it is still one of the important materials that have been investigated extensively.

Several physical and chemical techniques such as pulsed laser deposition (PLD), molecular beam epitaxy, R. F. sputtering, co-evaporation, spray pyrolysis technique and chemical vapor deposition (CVD) have been used to prepare superconducting thin films. The PLD method is known to be suitable for fabricating films with complex stoichiometry and become a potential method of fabricating high quality superconducting thin films suitable for electronic applications such as in Josephson junction based electronics and the second generation coated conductors. A significant effort has been done by researchers [5]-[8] to improve the critical temperature for textured and epitaxial HTSc films and the potential applications of thin films.

Recently, the effect of nano addition has been extensively studied to improve the superconducting properties such as nanoelements: (Ag, $\mathrm{Au}$, etc.), nanooxides $\left(\mathrm{SnO}_{2}, \mathrm{ZrO}_{2}, \mathrm{MgO}\right.$, etc.) [9] and nanocompound: $\left(\mathrm{NiFe}_{2} \mathrm{O}_{4}\right.$, $\mathrm{BiFeO}_{3}$, etc.) [10]. I. H. Gul et al. [11] studied the effect $\mathrm{Ag}_{2} \mathrm{CO}_{3}$ addition (0 - $25 \mathrm{wt} \%$ ) on the

$\mathrm{Bi}_{1.6} \mathrm{~Pb}_{0.4} \mathrm{Sr}_{2} \mathrm{Ca}_{2} \mathrm{Cu}_{3} \mathrm{O}_{10+\delta}$ (Bi-2223) and found the critical current density for the $25 \mathrm{wt} \%$ Ag doped samples increased by three times compared to the undoped sample. W. Abdeen, et al. [12] found that increasing the addition of nano-Ag up to $\mathrm{x}=1.5 \mathrm{wt} \%$ enhanced the phase formation and improved the superconducting transition temperature $T_{c}$ and the critical current density $J_{c}$. R. Mawassi et al. [13] studied the effect of Ag nanoparticles addition on the superconducting properties of $(\mathrm{Bi}, \mathrm{Pb})-2223$ phase. They found that the electrical and granular properties were greatly enhanced, indicating more efficient pinning mechanisms. An improvement of the critical current density of $229 \%$ was obtained with $\mathrm{x}=0.6 \mathrm{wt} \%$ while the superconducting transition temperature is improved by $2.5 \%$.

In this work, thin films of $\mathrm{Bi}(\mathrm{Pb})-\mathrm{Sr}-\mathrm{Ca}-\mathrm{Cu}-\mathrm{O}$ with $\mathrm{Ag}$ nanoparticles addition were post-annealed. The influence of optimal processing parameters on the formation of the superconducting single-phase (2223) oxide thin film in the Bi-based system was investigated. The samples were characterized by SEM, AFM, XRD and electrical resistance measurement.

\section{Materials and Methods}

Samples of $\mathrm{Bi}_{1.7} \mathrm{~Pb}_{0.3} \mathrm{Sr}_{2} \mathrm{Ca}_{2} \mathrm{Cu}_{3} \mathrm{O}_{10+\delta}$ with and without an addition of $\mathrm{Ag}$ nanoparticles were prepared by a conventional solid state reaction method. The stoichiometric amounts of high purity powders $(99.999 \%)$ of $\mathrm{Bi}_{2} \mathrm{O}_{3}$, $\mathrm{Pb}_{3} \mathrm{O}_{4}, \mathrm{Sr}\left(\mathrm{NO}_{3}\right)_{2}, \mathrm{CaO}$ and $\mathrm{CuO}, \mathrm{Ag}$ nanoparticles were added by weight percentages $(0.0,0.2,0.4,0.6,0.8$ and 1.0 weight \%). The powders were mixed together by using of mill machine (SPEX Industries Inc.-USA), for a period of (10) minute followed by manually grinding of powder using agate mortar and pestle for a (15) minute, The mixture homogenization takes place by adding a sufficient quantity of 2-propanol to form a paste during the process of grinding for about 30 minutes. The mixture was grounded to a fine powder and then calcined in air by using a tube furnace at $810^{\circ} \mathrm{C}$ for $24 \mathrm{~h}$ with a rate of $2^{\circ} \mathrm{C} / \mathrm{min}$. The mixture then pressed into pellets of diameter $13 \mathrm{~mm}$ and thickness $(2-3) \mathrm{mm}$ by using hydraulic press type (SPECAC) under a pressure of $0.7 \mathrm{GPa}$. The pellets were sintered at $845^{\circ} \mathrm{C}$ for $140 \mathrm{hr}$. These pellets were used as a target. BPSCCO target before and after addition of Ag nanoparticles was entered in vacuum chamber $10^{-2}$ mbar, and Q-switched Nd:YaG pulse laser operated at $1064 \mathrm{~nm}$ wavelength, $500 \mathrm{~mJ} /$ pulse, the distance between substrate and target $2 \mathrm{~cm}$ and $700 \mathrm{~mJ}$ pulse energy for frequency $5 \mathrm{~Hz}$. All samples were grown at an optimal p-type Si (111) substrate at room temperature. The as-deposited thin films were annealed in a tube furnace under $2 \mathrm{lit} / \mathrm{min}$ oxygen flow at $800^{\circ} \mathrm{C}$ for $1.5 \mathrm{~h}$ with heating and cooling rate of $5^{\circ} \mathrm{C} / \mathrm{min}$. Resistance-temperature data were obtained by using four point probe DC method at a temperature range $(77-300) \mathrm{K}$ to determine the critical temperature $\left(T_{c}\right)$. All samples were subjected to gross structural characterization by X-ray diffraction (XRD) (Shimadzu-6000, with $\mathrm{Cu}-\mathrm{K} \alpha$ source). A computer program was used to calculate the lattice parameters, based on Cohen's least square method. The surface morphology of the samples was carried out by scanning electron microscopy (SEM) performed by (FEI Co. system SN: 9922650-2013/Holland) and atomic force microscopy (AFM) type origin USA Model (AA300CSPM).

\section{Results and Discussion}

$\mathrm{X}$-ray diffraction pattern of samples with Ag nanoparticles addition $(\mathrm{x}=0.0,0.2,0.4,0.6,0.8$ and 1.0$)$ are shown in Figure 1. It is more suitable for pointing out the presence of both $\mathrm{Bi}(\mathrm{Pb})-2223$ and $\mathrm{Bi}(\mathrm{Pb})-2212$ phases with $\mathrm{Bi}(\mathrm{Pb})-2223$ being the dominant phase. To estimate the volume fraction of the present phases, we used the corresponding Bi-2212 and Bi-2223 peaks, in the following formulas [14] [15]: 


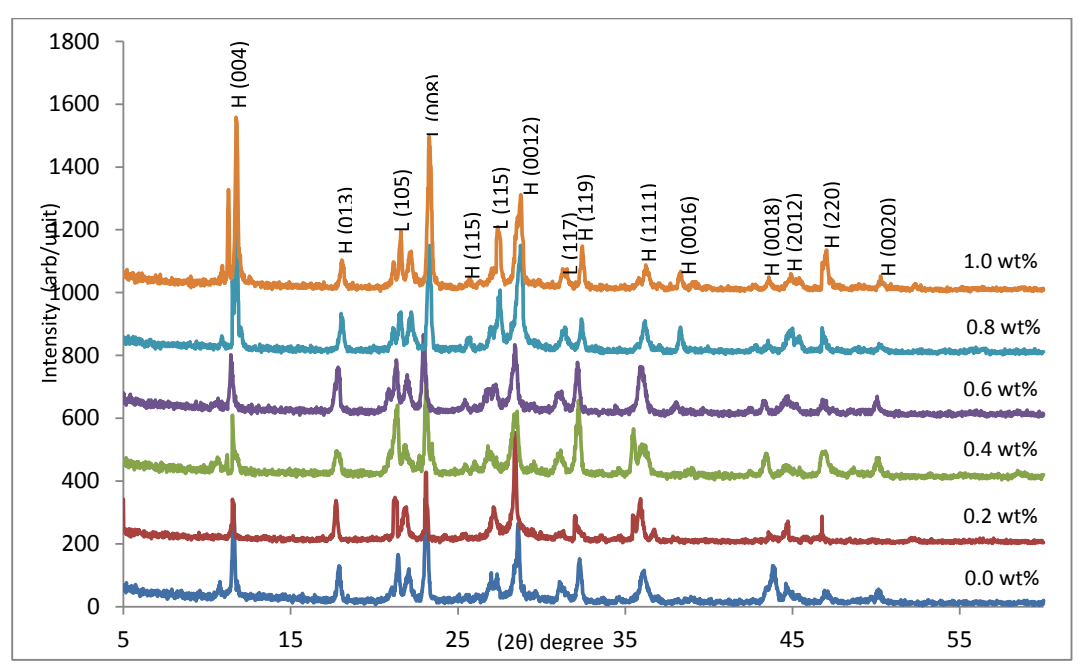

Figure 1. X-Ray diffraction patterns of (Bi, Pb)-2223 thin films for different Ag nanoparticles addition.

$$
\begin{aligned}
& V_{H}(\mathrm{Bi}-2223)=\frac{\sum I(2223)}{\sum I(2223)+\sum I(2212)} \times 100 \% \\
& V_{L}(\mathrm{Bi}-2212)=\frac{\sum I(2212)}{\sum I(2223)+\sum I(2212)} \times 100 \%
\end{aligned}
$$

Due to the annealing treatment of the films a crystalline order was established and an improvement of the films morphology, optimization of oxygen content and a change of the phase composition of the films have been obtained. It can be noticed that all films are well crystallized having an orthorhombic phase with $c$-axis oriented perpendicular to the film surface. The thermal treatment allows uniform diffusion $\mathrm{Bi}(\mathrm{Pb})-2223$ materials on $\mathrm{Si}$ (111) substrate forming smoother films. With increasing Ag nanoparticles addition to $1.0 \mathrm{w} \%$ a slight angular shift and sharpness of some peaks such as H (004), H (0012), and H (220) have been noticed. This may attribute to the change in the oxygen content of the films. Such behavior was also obtained by Ishii et al. [9] and Ahmed [14].

Thermal treatment of the films leads to facilitate growth, flattening, and density the material that produced much thinner films. The lattice constant of thin films was calculated using $(h k l)$ values of the strong peaks in the XRD patterns with the aid of Bragg's law. Increasing nano-Ag to $\mathrm{x}=1.0 \mathrm{wt} \%$ slightly enhanced the lattice parameters. The length may be expanded or contracted with the change of the electrons into antibonding orbital. Indeed, the behavior of the lattice constant may attribute to the displacement of Ag ions inside the structure. The variations of lattice parameters indicate the intercalation of oxygen species. This change of $a$ and $c$ effect on the volume of the unit cell and then causes variation of the density. It can be observed that the density value of the prepared films increases with the decreasing of $(V)$. The increase in volume $(V)$ is attributed to a larger number of Cu-O layers in the unit cell with the addition of Ag nanoparticles. The lattice parameters, unit cell volumes and the ratio c/a for the prepared films are listed in Table 1.

The critical temperature measurement performed by four-probe resistance measurement. The dimensions of films were about: thickness $(t) 190 \pm 5 \mathrm{~nm}$, the width of films $(b) 1 \mathrm{~cm}$ and the distance between two probe points $(d) 29.272 \times 10^{-6} \mathrm{~m}$. The value of the current flow in films is $1 \mathrm{~mA}$. So the final equation for films resistivity is:

$$
\rho=\frac{b t}{d} \frac{V}{I}
$$

Figure 2 show typical electrical resistance versus temperature relationships of the films with different nano-Ag addition. The electrical resistance initially decreases with decreasing temperature and then rapidly drops for a further decrease in the temperature, achieving zero resistance at the critical transition temperature. All 
Table 1. Lattice parameters and unit cell volumes of the prepared thin films with different Ag nanoparticles addition.

\begin{tabular}{cccccc}
\hline Nano-Ag wt\% & $\mathrm{a} \AA$ & $\mathrm{C} \AA$ & Volume V $(\AA)^{3}$ & $\frac{c}{a}$ & $\rho_{M}\left(\mathrm{gm} / \mathrm{cm}^{3}\right)$ \\
\hline 0.0 & 5.390257 & 36.92936 & 1075.3025 & 6.8511 & 1.518 \\
0.2 & 5.389867 & 37.04897 & 1090.5531 & 6.8738 & 1.536 \\
0.4 & 5.392585 & 37.11766 & 1098.9288 & 6.8830 & 1.547 \\
0.6 & 5.390064 & 37.05606 & 1093.7221 & 6.8749 & 1.554 \\
0.8 & 5.394833 & 37.11963 & 1098.0608 & 6.8805 & 1.584 \\
1.0 & 5.388705 & 37.12616 & 1096.7838 & 6.8896 & 1.594 \\
\hline
\end{tabular}

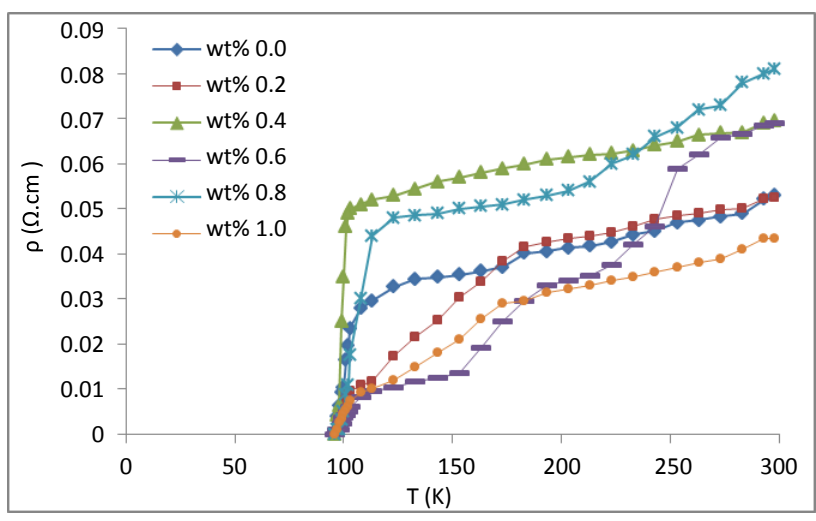

Figure 2. $\rho$ - $\mathrm{T}$ plots for pure and $\mathrm{Ag}$ nanoparticles added $\mathrm{Bi}_{1.7}$ $\mathrm{Pb}_{0.3} \mathrm{Sr}_{2} \mathrm{Ca}_{2} \mathrm{Cu}_{3} \mathrm{O}_{10}$ thin film samples.

films show superconducting behavior and the transition temperature for the films has increased with increasing nano-Ag addition to $\mathrm{x}=1.0 \mathrm{wt} \%$ except for $\mathrm{x}=0.6 \mathrm{wt} \%$ which shows $T_{c}$ less than $100 \mathrm{~K}$ as listed in Table 2, the transition from normal to superconducting state is not sharp, this may be attributed to the oxygen concentration fluctuation in grains, and the presence of inhomogeneity in the oxidation state of grains. The critical temperature of Bi-2223 materials is very much dependent on the oxygen concentration, it is interesting to notice that the resulting inhomogeneity in oxygen concentration would lead to variations in the structural parameters, such result was also obtained by Mua et al. [5].

The superconducting transition width $(\Delta T)$ is equal to $\left(T_{c}-T_{0}\right)$, this small value is defined as the measure of the quality or purity of the sample. Because of the existence of percolate paths which shortens out the current [13]. Thus, it can be notice that the value of $\Delta T$ for all samples increases with the increasing of nano-Ag addition, especially for the sample $\mathrm{x}=1.0 \mathrm{wt} \%$ which showed the highest value of the critical temperature, while the sample $\mathrm{x}=0.6 \mathrm{wt} \%$ shows the lowest values of $\Delta T$ and $T_{c}$, Figure 3 illustrate the relation between the critical temperature and the nano-Ag addition concentration. The thickness of the thin film samples could have the effect on the results of the critical temperature, grains size and growth of the film because if a crystal has its wide planar $c$ axis of the surface in contact with another surface (e.g. silver substrate, secondary phases, free surface or another BSCCO crystal), it can reduce the surface energy with the potential for so adhere to the surface. This mechanism, presented to the system with planar constraints, such as a 2212-Ag film, will result in a textured sample, depending on the thickness of the superconducting layer [5].

To clarify that Ag nanoparticles plays an important role in enhancement the $\mathrm{Bi}(\mathrm{Pb})-2223$ phase for thin film samples, also for checking the differences in the surface morphologies of the film, the surface morphology of different films was carried out by using AFM and SEM measurements, as shown in Figure 4, when bombing bulk samples for various additions of nano-Ag by PLD, the number of pulses applied to the metal target is 500 pulse. These samples show a clear feature of islands growth and nano-holes forming trenches between the growth islands, i.e. this mode may be correlated to the existence of clusters in the plasma [3] [16], it is attributed to the different epitaxial growth modes with strong chemical bonds or weak physical interactions with Si (111). However, ex-situ films nucleation follows a Volmer-Weber mechanism of growth, adatom-adatom interactions 
Table 2. Critical temperature transition width for different Ag nanoparticles addition thin films.

\begin{tabular}{cccccc}
\hline Ag nanoparticle wt\% & $T_{c}(\mathrm{~K})$ & $T_{0}(\mathrm{~K})$ & $\Delta T(\mathrm{~K})$ & \multicolumn{2}{c}{ Volume Fraction } \\
\cline { 4 - 6 } 0.0 & 100 & 98 & 2 & 59.85 & 40.15 \\
0.2 & 100.5 & 97 & 3.5 & 58.25 & 41.75 \\
0.4 & 101 & 97 & 4 & 57.83 & 42.17 \\
0.6 & 98 & 96 & 2 & 56.60 & 43.40 \\
0.8 & 102 & 97 & 5 & 64.86 & 35.14 \\
1.0 & 103.5 & 97 & 6.5 & 66.15 & 33.85 \\
\hline
\end{tabular}

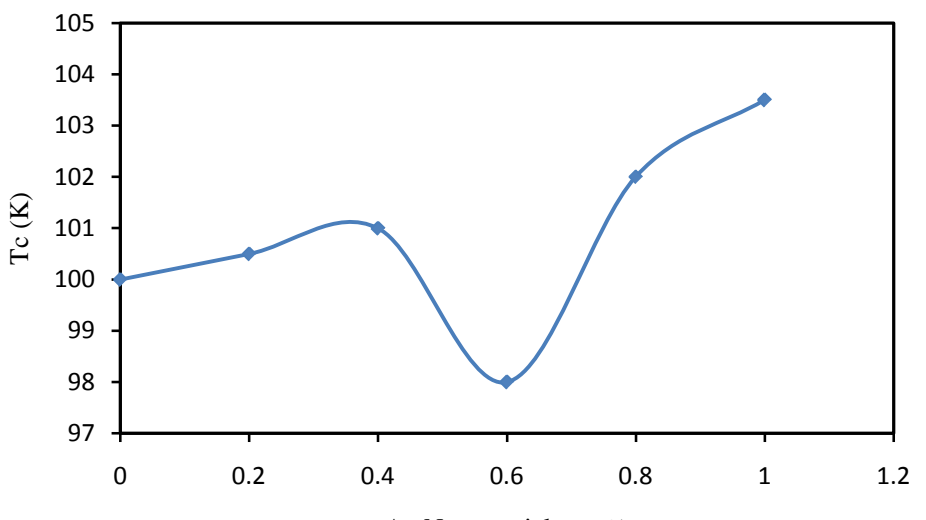

Ag Nanoparticles wt\%

Figure 3. Ag nanoparticles concentration versus critical temperature $T_{c}$ for all thin films.
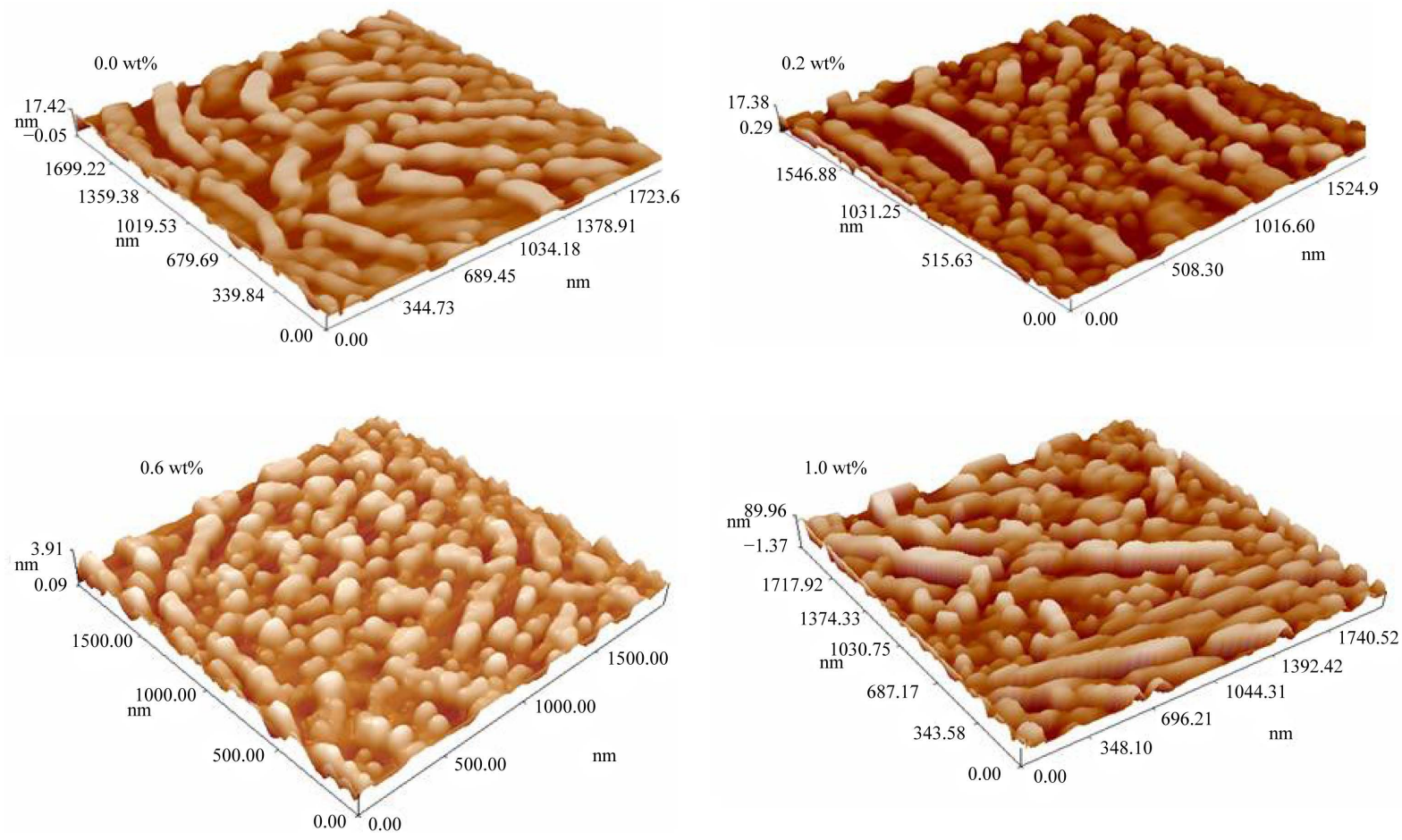

Figure 4. AFM surface images of $\mathrm{Bi}(\mathrm{Pb})-2223$ phase for different $\mathrm{Ag}$ nanoparticles addition, films were grown at $800^{\circ} \mathrm{C}$ on Si (111) substrate. 
are stronger than those of the adatom with the surface, leading to the formation of three-dimensional (3D) adatom clusters or islands [16] and after lateral grain growth and coalescence low angle grain boundaries remain which follow a zone improvement plan process leading to continuously reconstructed films, these results were in good agreement with that obtained by Obradors et al. [17], and Vitug et al. [18].

Characteristic of AFM for all films is the island structure, with an island diameter of typically $200-600 \mathrm{~nm}$, separated by deep trenches consisting of nano-size holes, which can be clearly visualized under high magnification SEM as well. Moreover, a fluctuate of average surface roughness (RA) and root mean square (RMS) values can be observed in Table 3, adding Ag nanoparticles to the compound resulted in small size of the average diameter, reduction of the structural defects (twin boundaries, terrace breadth, and stacking faults) and chemical imperfections such as oxygen deficiencies inside the grains.

The SEM micrographs of the cross-sectional view for $\mathrm{Bi}_{1.7} \mathrm{~Pb}_{0.3} \mathrm{Sr}_{2} \mathrm{Ca}_{2} \mathrm{Cu}_{3} \mathrm{O}_{10}$ and nano-Ag added films are shown in Figure 5. Superconducting grains are seen to be strongly connected with each other and the surface morphology of the films comprises of platelets and layered. The platelet-type features with some improvement to the grain alignment of samples are found in Ag nanoparticles added films which resulting the distribution of grains become uniform and homogenous microstructure, increasing the nano-Ag addition to $\mathrm{x}=1 \% \mathrm{wt}$ increases

Table 3. Average surface roughness, root mean square, and average diameter values for all films.

\begin{tabular}{cccc}
\hline (nano-Ag) $\mathrm{wt} \%$ & Sa (Roughness Average) $\mathrm{nm}$ & Sq (Root Mean Square) $\mathrm{nm}$ & Avg. Diameter $\mathrm{nm}$ \\
\hline 0.0 & 2.30 & 2.66 & 104.65 \\
0.2 & 2.71 & 3.13 & 86.59 \\
0.4 & 0.90 & 1.05 & 85.25 \\
0.6 & 0.51 & 0.59 & 77.90 \\
0.8 & 2.24 & 2.58 & 77.47 \\
1.0 & 1.51 & 1.79 & 74.98 \\
\hline
\end{tabular}
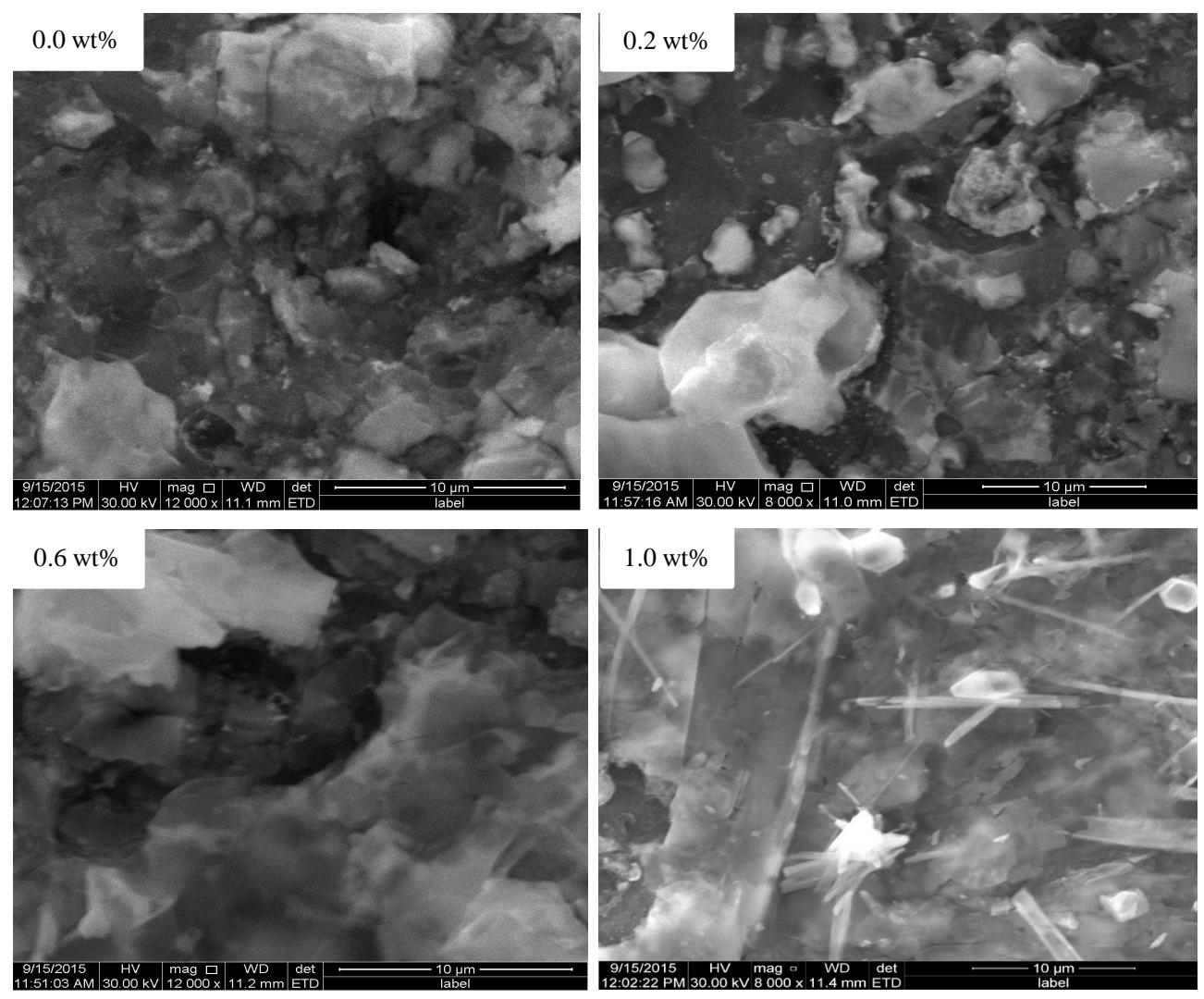

Figure 5. SEM micrographs of (Bi, Pb)-2223 phase for different Ag nanoparticles addition films. 
the formation of randomly bigger platelet grains size on the surface (compact platelets), forms of needle (or rod) and flowers were also observed, this may be able to establish connectivity between grains. Therefore, the increase in $T_{c}$ with the appropriate nano-Ag addition in the sample is associated with the enhancement of $\mathrm{Bi}(\mathrm{Pb})-$ 2223 phase formation, and form dense regions which improved links between grains.

Morphology of samples from SEM revealed that adding a noble element (Ag nanoparticle) is refers to advantage and promote in treatment and accelerated of $\mathrm{Bi}(\mathrm{Pb})-2223$ grain phase formation in these samples. The difference in the grain size and the distribution of grains on the surface of the samples indicate the influence of replacing of $\mathrm{Ag}^{1+}$ and $\mathrm{Pb}^{2+}$ together for $\mathrm{Bi}-2223$ on the morphology of the samples. The SEM image of high concentration such as $1.0 \mathrm{wt} \%$ of the nano-Ag specimen shows large size grains with thin plate-like and needle-like structures. These grain structures were aligned to make more dense and conductive sample. This result is in good agreement with the results obtained by Ahmed [14].

\section{Conclusion}

This paper reports on the effects of Ag nanoparticle addition on the superconducting properties of $\mathrm{Bi}_{1.7} \mathrm{~Pb}_{0.3} \mathrm{Sr}_{2} \mathrm{Ca}_{2} \mathrm{Cu}_{3} \mathrm{O}_{10}$ superconductor thin films that had been prepared via conventional PLD method by using high superconductor materials. $0.0-1.0 \mathrm{wt} \%$ of nano-Ag was added, by introducing nanoparticle within the structures of the films; the value of volume fraction, as well as $T_{c}$ could be increased. The highest volume fraction of the $\mathrm{Bi}(\mathrm{Pb})-2223$ phase $66.15 \%$ and the best value for $T_{c}$ of $103.5 \mathrm{~K}$ have been obtained from the sample with $1.0 \mathrm{wt} \%$ addition as against $100 \mathrm{~K}$ for the non-added samples. The XRD pattern shows that the addition of nanoparticle does not change the crystallographic structure of the samples and remain in the orthorhombic unit cell.

\section{References}

[1] Maeda, H., Tanaka, Y., Fukutomi, M. and Asano, T. (1988) A New High-T Oxide Superconductor without a Rare Earth Element. Japanese Journal of Applied Physics, 27, L209-1210. http://dx.doi.org/10.1143/JJAP.27.L209

[2] Michel, C., Hervieu, M., Borel, M.M., Grandin, A., Deslandes, F., Provost, J. and Raveau, B. (1987) Superconductivity in the Bi-Sr-Cu-O System. Zeitschrift für Physik B, 68, 421-423. http://dx.doi.org/10.1007/BF01471071

[3] Jannah, A.N., Halim, S.A. and Abdullah, H. (2009) Superconducting Properties of BSCCO Thin Films by Pulsed Laser Deposition. ISSN European Journal of Scientific Research, 29, 438-446.

[4] Takahashi, N., Koikitu, A., Seki, H. and Kamioka, Y. (1994) The Effect of Pb Addition on Bi-Sr-Ca-Cu-O Superconducting Thin Films Prepared by the Mist Microwave-Plasma Chemical Vapor Deposition Method. Journal of Crystal Growth, 144, 48-53. http://dx.doi.org/10.1016/0022-0248(94)90008-6

[5] Mua, N.T., Sundaresan, A., Kman, N. and Dung, D.D. (2014) Influence of Preparation Conditions on Superconducting Properties of Bi-2223 Thin Films. Bulletin Materials Science, 37, 19-25. http://dx.doi.org/10.1007/s12034-014-0627-8

[6] Wong-Ng, W. and Cook, L.P. (2000) Effect of Ag on the Primary Phase Field of the High-Tc(Bi, Pb)-2223 Superconductor. Journal of Materials Research, 15, 296-305. http://dx.doi.org/10.1557/JMR.2000.0048

[7] Ki, Y.S. and Min, S.L. (2006) The Effect of a Large Amount of Ag Introduced into the $\mathrm{Bi}_{1.84} \mathrm{~Pb}_{0.34} \mathrm{Sr}_{1.91} \mathrm{Ca}_{2.03} \mathrm{Cu}_{3.06} \mathrm{O}_{10+\delta}\left(110 \mathrm{~K}\right.$ Phase) High- $\mathrm{T}_{\mathrm{c}}$ Superconductor. Superconductor Science and Technology, 19, 1253.

[8] Hermiz, G.Y., Abbass, M.M. and Gilioli, E. (2009) Superconductivity of $\left(\mathrm{Bi}_{0.7} \mathrm{~Pb}_{0.3}\right)_{2} \mathrm{Ag}_{\mathrm{x}} \mathrm{Sr}_{2} \mathrm{Ca}_{2} \mathrm{Cu}_{3} \mathrm{O}(0<\mathrm{X}<0.5)$. Atti Della, Fondazione Giorgio Ronchi, Anno Lxiv, 1-8.

[9] Ishii, A. and Hatano, T. (2000) Preparation of High Quality $\mathrm{Bi}_{2} \mathrm{Sr}_{2} \mathrm{CaCu}_{2} \mathrm{O}_{8+\delta}$ Thin Films on a MgO Substrate by Pulsed Laser Ablation and Post-Annealing Recrystallization of Films Accompanying In-Plane Rotation of a and b Axes. Physica C: Superconductivity, 340, 173-177. http://dx.doi.org/10.1016/S0921-4534(00)00385-3

[10] Suvasis, S. (2011) Studies on Superconductor/Nano Composite of BSCCO/BiFeO . M.Sc. Thesis, Department of Physics, National Institute of Technology Rourkela, India.

[11] Gul, I.H., Amin, F., Abbasi, A.Z., Anis-ur-Rehman, M. and Maqsood, A. (2006) Effect of $\mathrm{Ag}_{2} \mathrm{CO}_{3}$ Addition on the Morphology and Physical Properties of Bi-Based (2223) High- $\mathrm{T}_{\mathrm{C}}$ Superconductors. Physica C: Superconductivity and Its Applications, 449, 139-147. http://dx.doi.org/10.1016/j.physc.2006.08.004

[12] Abdeen, W., Mohammed, N.H., Awad, R., Mahmoud, S.A. and Hasebbo, M. (2012) Influence of Nano-Ag Addition on Phase Formation and Electrical Properties of $\left(\mathrm{Cu}_{0.5} \mathrm{Tl}_{0.5}\right)-1223$ Superconducting Phase. Journal of Superconductivity and Novel Magnetism, 26, 623-631. http://dx.doi.org/10.1007/s10948-012-1803-y 
[13] Mawassi, R., Marhaba, S., Roumié, M., Awad, R., Kork, M. and Hassan, I. (2014) Improvement of Superconducting Parameters of $\mathrm{Bi}_{1.8} \mathrm{~Pb}_{0.4} \mathrm{Sr}_{2} \mathrm{Ca}_{2} \mathrm{Cu}_{3} \mathrm{O}_{10+\delta}$ Added with Nano-Ag. Journal of Superconductivity and Novel Magnetism, 27, 1131-1142. http://dx.doi.org/10.1007/s10948-013-2408-9

[14] Ahmed, A.R. (2015) Study of the Electrical and Structural/Micro Structural Properties of $\mathrm{Bi}_{2-\mathrm{x}} \mathrm{Ag}_{\mathrm{x}} \mathrm{Ba}_{2-\mathrm{y}} \mathrm{Sr}_{\mathrm{y}} \mathrm{Ca}_{2} \mathrm{Cu}_{3} \mathrm{O}_{10+\delta}$ System. IISTE Advances in Physics Theories and Applications, 39, 33-42.

[15] Zargar, S.M. and Ghahfarokhi, M.S. (2011) A Study of the Magnetic Properties of $\mathrm{Bi}_{1.64-\mathrm{x}} \mathrm{Pb}_{0.36} \mathrm{Cd}_{\mathrm{x}} \mathrm{Sr}_{2} \mathrm{Ca}_{2} \mathrm{Cu}_{3} \mathrm{O}_{\mathrm{y}} \mathrm{Su}_{-}$ perconductor. Journal of Superconductivity and Novel Magnetism, 24, 1505-1511. http://dx.doi.org/10.1007/s10948-010-0899-1

[16] Li, A.H., Ionescu, M., Liu, H.K., Silver, T., Wang, X.L. and Dou, S.X. (2005) Microstructures and Enhancement of Critical Current Density in $\mathrm{Yba}_{2} \mathrm{Cu}_{3} \mathrm{O}_{7}$ Thin Films Grown by Pulsed Laser Deposition on Various Single Crystal Substrates Modified by Ag Nano-Dots. IEEE Transactions on Applied Superconductivity, 15, 3946-3049. http://dx.doi.org/10.1109/TASC.2005.848731

[17] Obradors, X., Martínez-Julián, F., Zalamova, K., Vlad, V.R., Pomar, A., Palau, A., Llordés, A., Chen, H., Coll, M., Ricart, S., Mestres, N., Granados, X., Puig, T. and Rikel, M. (2012) Nucleation and Mesostrain Influence on Percolating Critical Currents of Solution Derived $\mathrm{YBa}_{2} \mathrm{Cu}_{3} \mathrm{O}_{7}$ Superconducting Thin Films. Physica C: Superconductivity and Its Applications, 482, 58-67. http://dx.doi.org/10.1016/j.physc.2012.04.020

[18] Vitug, J., Lampa, K.I., Olaya, C., DeVero, J., Santos, G.N., Sarmago, R. and Garcia, W. (2012) Nanosecond and Femtosecond Laser Ablation of Pure and Y-Doped BSCCO. SPP Footer, 1-4.

https://www.academia.edu/1181897/Nanosecond_and_femtosecond_laser_ablation_of_pure_and_Y-doped_BSCCO 